\title{
Benefits of High-Volume Medical Oncology Care for Noncurable Pancreatic Adenocarcinoma: A Population-Based Analysis
}

Julie Hallet, MD, MSca,b,c,d; Laura Davis, MScc; Alyson Mahar, PhDe; Michail Mavros, MD'; Kaitlyn Beyfuss, MScc; Ying Liu, MSc ${ }^{d}$; Calvin H.L. Law, MD, MPH ${ }^{a, b, c}$; Craig Earle, MD, MSc ${ }^{a, c, d}$; and Natalie Coburn, MD, MPH $H^{a, b, c, d}$

\section{ABSTRACT}

Background: Although pancreatic adenocarcinoma (PA) surgery performed by high-volume (HV) providers yields better outcomes, volume-outcome relationships are unknown for medical oncologists. This study examined variation in practice and outcomes in noncurative management of PA based on medical oncology provider volume. Methods: This population-based cohort study linked administrative healthcare datasets and included nonresected PA from 2005 through 2016. The volume of PA consultations per medical oncology provider per year was divided into quintiles, with HV providers ( $\geq 16$ patients/year) constituting the fifth quintile and lowvolume (LV) providers the first to fourth quintiles. Outcomes were receipt of chemotherapy and overall survival (OS). The BrownForsythe-Levene (BFL) test for equality of variances was performed to assess outcome variability between provider-volume quintiles. Multivariate regression models were used to examine the association between management by HV provider and outcomes. Results: A total of 7,062 patients with noncurable PA consulted with medical oncology providers. Variability was seen in receipt of chemotherapy and median survival based on provider volume (BFL, $P<.001$ for both), with superior 1-year OS for HV providers $(30.1 \% ; 95 \% \mathrm{Cl}$, $27.7 \%-32.4 \%)$ compared with LV providers $(19.7 \% ; 95 \% \mathrm{Cl}$, $18.5 \%-20.6 \%)(P<.001)$. After adjustment for age at diagnosis, sex, comorbidity burden, rural residence, income, and diagnosis period, $\mathrm{HV}$ provider care was independently associated with higher odds of receiving chemotherapy (odds ratio, $1.19 ; 95 \% \mathrm{Cl}, 1.05-1.34$ ) and with superior OS (hazard ratio, $0.79 ; 95 \% \mathrm{Cl}, 0.74-0.84$ ). Conclusions: Significant variation was seen in noncurative management and outcomes of PA based on provider volume, with management by an HV provider being independently associated with superior OS and higher odds of receiving chemotherapy. This information is important to inform disease care pathways and care organization. Cancer care systems could consider increasing the number of $\mathrm{HV}$ providers to reduce variation and improve outcomes.

J Natl Compr Canc Netw 2020;18(3):297-303 doi: 10.6004/jnccn.2019.7361

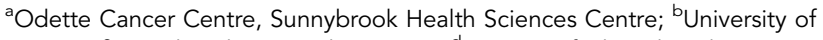
Toronto; 'Sunnybrook Research Institute; ${ }^{d}$ Institute of Clinical Evaluative Sciences, Toronto, Ontario; and 'University of Manitoba, Winnipeg, Manitoba, Canada.

\section{Background}

As medical and surgical therapies advance, cancer care has become increasingly complex. Clinical volume is an important construct in the delivery of specialized care, and provider volume has been associated with improved outcomes of cancer surgery. ${ }^{1-3}$ This finding has impacted policy through implementation of regionalized care networks for surgery. ${ }^{4-9}$

Beyond surgical therapy, patient volume for nonsurgical interventions may be important to consider in the delivery of high-quality cancer care. Increased clinical volume has been associated with higher quality of care and better outcomes in hematologic cancers. ${ }^{10-14}$ However, whether medical oncologists' clinical experience and volume affect patterns of care and outcomes of systemic therapy in solid cancers is unknown. In a review of volume outcome in cancer care, the Institute of Medicine outlined the need to examine volume-outcome relationships in both surgical and medical interventions. ${ }^{15}$

Noncurative management of pancreatic adenocarcinoma (PA) represents a good opportunity to study clinical volume and outcomes in systemic therapy. PA is a high-fatality cancer; in 2018, it was the fourth leading cause of cancer-related death in the United States. ${ }^{16}$ Most patients present at advanced stages and require palliative-intent management focused on systemic therapy to improve symptoms and survival. ${ }^{17}$ The introduction of multiagent systemic regimens with improved efficacy but higher toxicity profiles has increased the complexity of noncurative management of PA. ${ }^{18,19}$ Balancing guidelines that recommend chemotherapy with patient factors such as age or higher comorbidity burden is thus becoming increasingly challenging. ${ }^{17}$ Finally, the long-lasting stigma of PA as a fatal cancer with few therapeutic options of limited efficacy may still lead to nihilism-driven care

See JNCCN.org for supplemental online content. 
delivery, depending on clinical experience. Current management of PA requires more-complex treatment planning and management of toxicities, and familiarity with a high-fatality cancer. All of these considerations may benefit from high-volume $(\mathrm{HV})$ provision of care. We conducted a population-based study to examine the relationship between provider volume and patterns of care and survival in the palliative management of PA.

\section{Methods}

\section{Study Design}

Using data linked from prospectively maintained administrative databases stored at the Institute for Clinical Evaluative Sciences (ICES) in Ontario, Canada, we conducted a population-based cohort study. Under the Canada Health Act, the Ontario population benefits from universally accessible and publicly funded healthcare through the Ontario Health Insurance Plan (OHIP). ${ }^{20}$ This study was approved by the Sunnybrook Health Sciences Centre Research Ethics Board and met the data confidentiality and privacy guidelines of ICES.

\section{Data Sources}

This study used several linked administrative datasets. The Ontario Cancer Registry includes all patients with a cancer diagnosis in Ontario since $1964^{21}$; the reliability of the data has previously been reported. ${ }^{21-23}$ The Registered Persons Database (RPDB) contains vital status and demographic data. ${ }^{22}$ Information regarding health services is included in the Canadian Institute for Health Information (CIHI) Discharge Abstract Database for acute inpatient hospitalizations; the National Ambulatory Care Reporting System for same-day surgery admissions, emergency department visits, and oncology clinic visits; and the OHIP claims database for billing from healthcare providers. ${ }^{24}$ The Cancer Activity Level Reporting dataset includes chemotherapeutics and medications administered to patients with cancer. These databases have been validated for a variety of diagnoses and services. ${ }^{24}$ The datasets were linked using unique encoded identifiers.

\section{Study Population and Cohort}

This study was conducted in all patients with a valid OHIP number diagnosed from 2005 to 2016. Patients with a new diagnosis of PA were identified in the Ontario Cancer Registry using ICD-O-3 codes, and we retained only patients who did not undergo curative-intent pancreatectomy (supplemental eTable 1, available with this article at JNCCN.org). Patients were excluded if they died before or on the date of diagnosis, had another cancer diagnosis before or after PA diagnosis, or were aged $\leq 18$ or $\geq 99$ years at diagnosis. Finally, patients were included if they were seen by a medical oncologist between diagnosis and end of follow-up (death, last clinical encounter, or end of study as of March 31, 2017), defined using OHIP claims as $\geq 1$ encounters with a medical oncologist. Any physician who submitted billing claims for chemotherapy administration codes (G281, G339, G345, G359, G381) during the study period was classified as a medical oncologist. ${ }^{23}$

\section{Exposure}

The main exposure of interest was the provider volume of each medical oncologist seeing patients in the cohort. Provider volume was the number of new noncurative PA consultations seen per year per provider over the study period. Each patient was assigned to one provider; if a patient saw more than one provider, the provider seen most often was assigned. Patients were divided into quintiles based on the provider volume of their medical oncologist in order to evaluate variability in outcomes across a continuum of provider volume; HV providers were assigned to the fifth quintile (highest), and lowvolume (LV) providers were assigned to the first to fourth quintiles.

\section{Covariates}

Age and sex were abstracted from the RPDB. Rural living was determined by the postal code of residence. ${ }^{25} \mathrm{In}$ come quintile was based on the median income of a patient's postal code of residence using national census data. ${ }^{24,26}$ The comorbidity burden was measured using the Johns Hopkins Adjusted Clinical Group system score. The 32 aggregated diagnosis groups were summed to create a total score, then dichotomized with a cutoff of 10 for high comorbidity burden, consistent with previous reports. ${ }^{27,28}$ Time period of diagnosis used year of diagnosis, categorized as 2005 through 2010 and 2011 through 2016, to account for temporal changes in management after outcomes of treatment with FOLFIRINOX (leucovorin/fluorouracil/irinotecan/oxaliplatin) and nabpaclitaxel chemotherapy regimens. ${ }^{18,19}$

\section{Outcome Measures}

Receipt of chemotherapy was determined by identifying patients for whom at least 2 chemotherapy infusions were billed from the date of diagnosis to end of followup. ${ }^{29-31}$ Overall survival (OS) was measured from date of diagnosis to date of death according to the RPDB. The end of follow-up was defined as the date of death, date of last contact, or March 31, 2017, offering an opportunity for a minimum of 12 months of follow-up for all patients.

\section{Statistical Analysis}

Descriptive analyses were used to define baseline characteristics and outcomes. Categorical variables were reported as absolute number and percent, and 
continuous variables were reported as mean with SD or median with interquartile range (IQR). Comparison testing was undertaken using the chi-square test for categorical variables and the Kruskal-Wallis or $t$ test for continuous variables. Kaplan-Meier methods were used for OS analysis, ${ }^{32}$ and OS curves were compared between provider volume groups using the log-rank test.

The median proportion of patients receiving chemotherapy and median OS were evaluated across provider volume quintiles to appreciate variability. The Brown-Forsythe-Levene (BFL) test was used to assess for equality of variance across quintile groups to determine whether more variation existed than would be expected by chance alone. ${ }^{33}$ Variance was examined to appreciate variation based on provider volume.

Multivariable regression models were constructed to assess the association between provider volume and outcomes. Relevant demographic and clinical characteristics were identified a priori as potential confounders of the relationship between provider volume and outcomes. The variables were selected based on clinical relevance (markers of complexity of cancer care) and existing literature (known relationship with OS for PA). The following covariates were included: age at diagnosis (categorical), sex, comorbidity burden, income quintile, residence (urban vs rural), and diagnosis period (2005-2010 vs 2011-2016). Logistic regression was performed to determine the association between provider volume and receipt of chemotherapy and Cox proportional hazards regression was used to determine the association with survival, and results were reported as main effect adjusted odds ratios and hazard ratios (HRs) with $95 \%$ confidence intervals, respectively.

Statistical significance was set at $P \leq .05$. All analyses were conducted using SAS Enterprise Guide 6.1 (SAS Institute Inc).

\section{Results}

A total of 7,062 patients with PA who did not undergo resection and saw a medical oncologist were included in the final study cohort (supplemental eFigure 1). Median follow-up was 5 months (IQR, 2.3-10.8 months). Median medical oncology provider volume was 4 patients per year (range, 1-55 patients/year) (supplemental eTable 2). HV (fifth quintile) was defined as consulting on $\geq 16$ patients per year (supplemental eTable 3). Overall, $72.3 \%$ $(n=5,151)$ of patients had $\geq 2$ encounters with medical oncology providers, including $71.0 \%$ in the LV group and $80.6 \%$ in the HV group.

Patients receiving care from HV providers $(n=1,420)$ were more likely to be in younger age groups, live in urban areas, and be diagnosed in more recent years (Table 1). Of patients treated by LV providers, $9.2 \%$ $(n=475)$ also had a consultation with a HV provider after their diagnosis. Over the study period, 11 (3.1\%) of 356 providers were $\mathrm{HV}$ providers (Figure 1). Although numbers cannot be reported due to confidentiality and privacy guidelines for managing small cells $(n \leq 6)$, no difference was observed in provider demographic, training, or practice characteristics between HV and LV providers.

The median proportion of patients receiving chemotherapy varied across quintiles of provider volume, ranging from $44 \%$ in the first quintile to $47 \%$ in the fifth quintile (HV). The narrower IQR with increasing provider volume quintiles indicated potential reduction in variation with increasing provider volume (Figure 2). The BFL test showed significant differences in variance across quintiles $(P<.001)$. Patients treated by providers in the higher-volume quintiles received chemotherapy for longer periods, with medians of 2.3 months (IQR, 0.66.0 months) for the first quintile, 2.4 months (IQR, 0.95.8 months) for the second quintile, 3.0 months (IQR, 1.2-7.1 months) for the third quintile, 3.0 months (IQR, 0.9-6.7 months) for the fourth quintile, and 3.7 months (IQR, 1.5-7.9 months) for the fifth quintile $(P<.001)$. After adjusting for age, sex, comorbidity burden, income, rural residence, and diagnosis period, care by a HV provider was independently associated with higher odds of receiving chemotherapy (adjusted odds ratio, 1.19; 95\% CI, 1.06-1.34). Duration of chemotherapy was longer in the 2011-2016 time period, with median values of 4.9 months (IQR, 1.8-9.2 months) compared with 2.8 months (IQR, 1.4-6.5 months) in 2005-2010 for HV providers and 3.6 months (IQR, 1.3-8.2 months) compared with 2.1 months (IQR, 0.7-4.7 months) in 2005-2010 for LV providers. Care by $\mathrm{HV}$ versus $\mathrm{LV}$ providers still yielded significantly longer chemotherapy duration in 2011-2016 $(P<.001)$.

Median survival also varied across quintiles of provider volume, with superior survival in the fifth quintile (7.5 months) compared with the first to fourth quintiles (4.1-4.9 months) (Figure 3). Evaluation of IQRs showed reduced ranges in higher quintiles, with the inferior border of the fifth quintile IQR (6.6 months) superior to the higher borders of IQRs for the first to fourth quintiles (5.8-6.2 months). The BFL test showed significant differences in variance $(P<.001)$. OS was superior for patients seen by HV providers, with 1-year OS of $30.1 \%$ (95\% CI, 27.7\%-32.4\%) compared with $19.7 \%$ (95\% CI, $18.5 \%-20.6 \%)$ for $L V$ providers $(P<.001)$ (Figure 4$)$. After adjustment for age at diagnosis, sex, comorbidity burden, income, rural residence, and diagnosis period, receipt of care from a HV provider was independently associated with superior OS (HR, 0.79; 95\% CI, 0.74-0.84).

\section{Discussion}

In this population-based analysis, we observed a wide distribution in the number of patients with PA seen annually by each medical oncology provider, and 


\begin{tabular}{|c|c|c|c|c|}
\hline & $\begin{array}{c}\text { All Providers } \\
\text { n (\%) }\end{array}$ & $\begin{array}{c}\text { Low-Volume }^{\text {L }} \\
\text { Provider Cohort } \\
\text { n (\%) }\end{array}$ & $\begin{array}{c}\text { High-Volume }^{\mathrm{b}} \\
\text { Provider Cohort } \\
\text { n (\%) }\end{array}$ & $P$ Value \\
\hline Patients, $n$ & 7,062 & 5,642 & 1,420 & \\
\hline Age at diagnosis, y & & & & $<.001$ \\
\hline$\leq 60$ & $1,874(26.5)$ & $1,427(25.3)$ & 447 (31.5) & \\
\hline $61-70$ & $2,087(29.6)$ & $1,625(28.8)$ & $462(32.5)$ & \\
\hline $71-80$ & $2,092(29.6)$ & $1,726(30.6)$ & $366(25.8)$ & \\
\hline$\geq 81$ & $1,009(14.3)$ & $864(15.3)$ & $145(10.2)$ & \\
\hline Sex & & & & .10 \\
\hline Female & $3,375(47.8)$ & $2,724(48.3)$ & $651(45.8)$ & \\
\hline Male & $3,687(52.2)$ & $2,918(51.7)$ & $769(54.2)$ & \\
\hline Residence & & & & .02 \\
\hline Urban & $6,136(86.9)$ & $4,870(86.4)$ & $1,266(89.2)$ & \\
\hline Rural & $926(13.1)$ & $772(13.7)$ & $154(10.8)$ & \\
\hline Comorbidity burden & & & & .62 \\
\hline$A D G<10$ & $4,705(66.6)$ & $3,751(66.5)$ & $954(67.2)$ & \\
\hline$A D G \geq 10$ & $2,357(33.4)$ & $1,891(33.5)$ & $466(32.8)$ & \\
\hline Income quintile & & & & .03 \\
\hline 1st, lowest & 1,098 (19.4) & $243(17.2)$ & $1,341(19.0)$ & \\
\hline 2nd & $1,176(20.8)$ & $302(21.3)$ & $1,478(20.9)$ & \\
\hline $3 r d$ & $1,173(20.8)$ & $263(18.5)$ & $1,436(20.3)$ & \\
\hline 4th & $1,153(20.4)$ & $307(21.6)$ & $1,460(20.7)$ & \\
\hline 5th, highest & $1,042(18.5)$ & $305(21.5)$ & $1,347(19.1)$ & \\
\hline Diagnosis period & & & & .03 \\
\hline 2005-2010 & $3,333(47.2)$ & $2,700(47.9)$ & $633(44.6)$ & \\
\hline $2011-2016$ & $3,729(52.8)$ & $2,942(52.1)$ & $787(55.4)$ & \\
\hline
\end{tabular}

Abbreviation: ADG, aggregated diagnosis group.

$a<16$ patients per year.

$b \geq 16$ patients per year.

variation in receipt of chemotherapy and survival based on provider volume. Care by an HV provider $(\geq 16$ patients/year) was independently associated with a $20 \%$ increase in the odds of receiving chemotherapy. It was also associated with superior OS, with an adjusted HR of 0.79 (95\% CI, 0.74-0.84). Although this effect estimate may seem small, the large sample size in this study allowed detection of significant effect. Moreover, the observed differences are similar to the effect estimates observed for systemic therapies now established as standard of care in gastrointestinal oncology. ${ }^{19,34-36}$ The magnitude of the effect is also consistent with the survival differences observed for HV cancer surgery determined using retrospective population data, which have led to policy changes in specialized surgical cancer care. ${ }^{1,3}$

This study represents an important addition to the literature by providing the first insight into how oncologists' patient volume impacts outcomes among those with solid cancers. The association of better survival with increased clinical volume has been identified in hematologic oncology within populations and single institutions. ${ }^{10,12-14}$ However, this has not been addressed for nonhematologic cancers at the provider level. The Ontario jurisdiction offered a unique opportunity to study this question, with data on all therapies, consultations, and outcomes reliably available for an entire population.

Systemic therapy for PA is crucial in improving symptoms and survival. ${ }^{18,19}$ Guidelines for palliative management of PA include triplet and doublet therapies in patients with ECOG performance status of 0 to 1 with a favorable comorbidity profile, and single-agent gemcitabine in those with ECOG performance status of 2 or with comorbidities precluding other regimens. ${ }^{17,37}$ Most patients have an indication for systemic therapy. However, across provider volume quintiles, only $44 \%$ to $47 \%$ of patients with PA received systemic treatment, with 


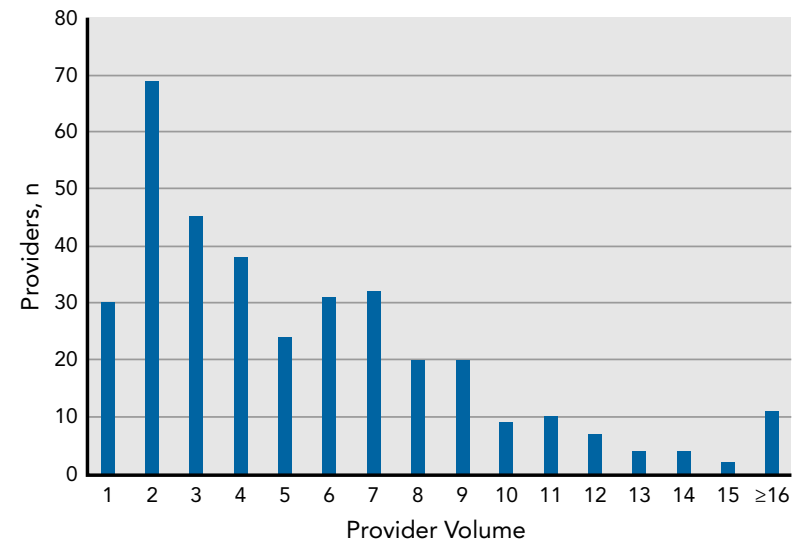

Figure 1. Distribution of providers $(n=356)$ by provider volume (patients seen per year).

increased likelihood of treatment associated with HV providers. Nonreceipt of therapy may be necessary when chemotherapy is not feasible or not aligned with patient preferences. Although we could not decipher decision-making specifics, we adjusted for patientlevel characteristics that may influence patient and physician decisions, including age, sex, and comorbidity burden.

Variation in therapy delivery can create inequities in effective care and patient safety. ${ }^{38}$ Unwarranted variation, referring to the proportion of variation that is explained not by difference in population but rather by quality, appropriateness, and efficiency of healthcare, should therefore be limited. ${ }^{39}$ Differential availability of resources was not a cause of variation in our study, because both recommendations and universal drug funding for all regimens have been in place since release of the trials. Case mix does not fully explain variations in

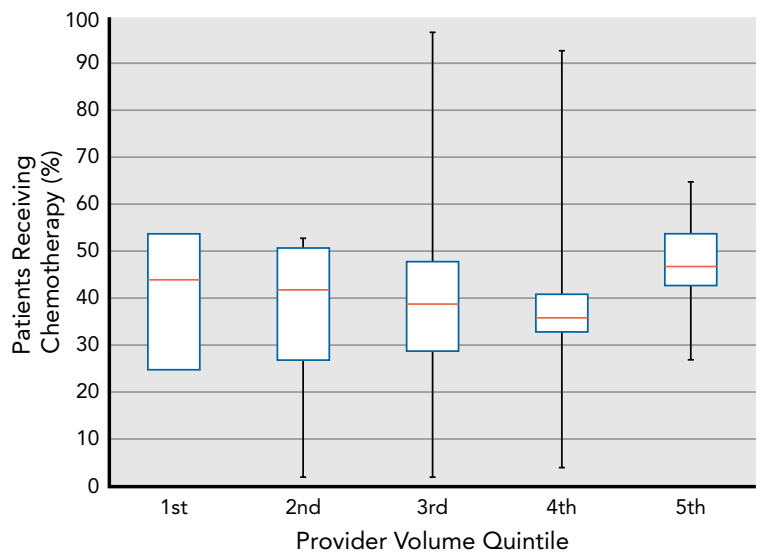

Figure 2. Median proportion of patients receiving chemotherapy. Orange line represents the median. Boxes represent interquartile range and vertical lines represent range.

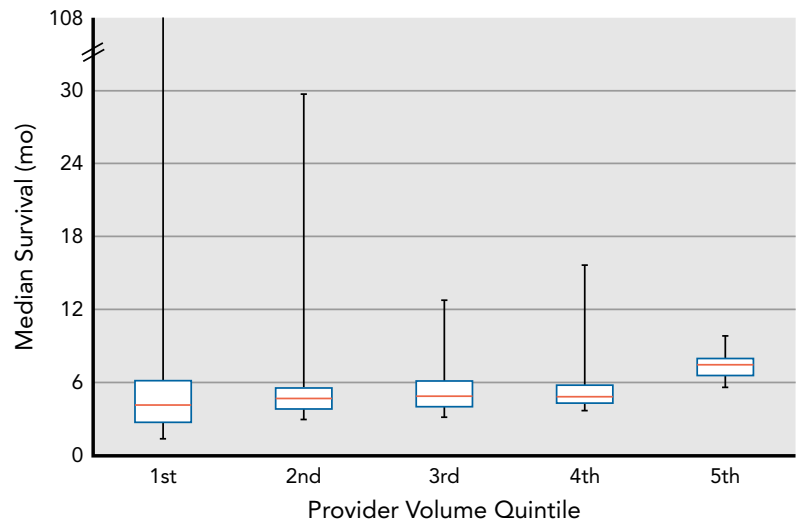

Figure 3. Median overall survival, stratified by provider volume quintile. Orange line represents the median. Boxes represent interquartile range and vertical lines represent range.

care either. However, the role of individual physicians' preferences is a recognized source of variation for medical interventions. ${ }^{40}$ One of the hypothesized main drivers of this variation is misinterpretation or misapplication of evidence and clinical information. ${ }^{41}$ Indeed, within a single HV institution, quality of care and survival have been linked to individual providers' experience and volume in the care of lymphoma. ${ }^{14} \mathrm{Al}-$ though the indication for systemic therapy is established for PA, the best timing, perception of real-life benefits for a high-fatality malignancy, and appreciation of the risk-benefit balance may not be the same across providers.

$\mathrm{HV}$ care was also associated with better survival. We could not fully account for potential referral biases, wherein patients who are more motivated or better performing may seek out HV providers. Importantly,

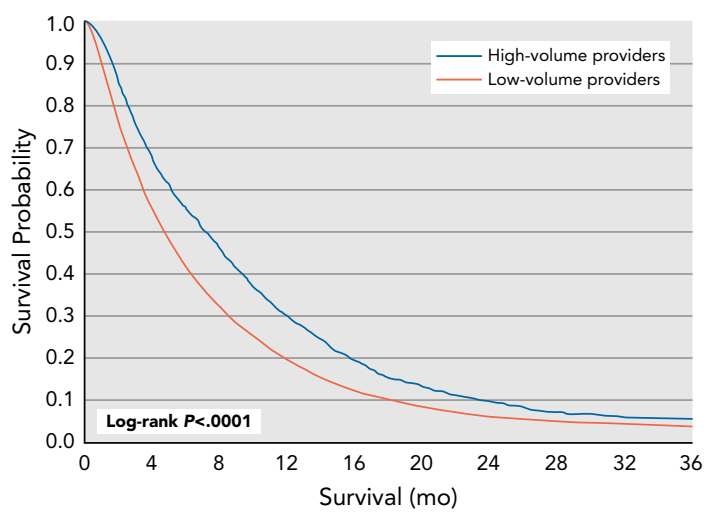

Number at risk

$\begin{array}{lllllllllll}\text { U High-volume } & 1,420 & 967 & 657 & 429 & 272 & 178 & 125 & 87 & 69 & 64\end{array}$ $\begin{array}{lllllllllll}\text { n Low-volume } & 5,640 & 3,152 & 1,835 & 1,109 & 666 & 431 & 307 & 239 & 196 & 162\end{array}$

Figure 4. Overall survival, stratified by receipt of care from low-volume and high-volume providers. 
clinical volume is likely associated with access to and enrollment in clinical trials, potentially associated with improved survival. Rather than a confounder, this may be an underlying mechanism of the observed disparity. Indeed, guidelines outline the need for every patient to be offered participation in clinical trials. ${ }^{17}$ Volume itself may not produce good or bad outcomes; rather, it may be a proxy measure for other factors, such as experience, processes of care, patient support, and access to clinical trials. ${ }^{42,43}$ Going forward, the ability to structure care delivery to improve outcomes will require an examination of what HV providers do differently, which was beyond the scope of this study.

An organization of care that focuses on $\mathrm{HV}$ providers must avoid barriers to access to this service. We focused on provider-level volume so that the results may be actionable within institutions and facilitate care close to home. It is acknowledged that when a volume-outcome relationship exists, the exact threshold is not always clear. We defined high provider volume using quintiles, but other stratifications have been used. ${ }^{42}$ The threshold of 16 patients per year is consistent with thresholds established in surgical cancer care and represents 4 times the median provider volume over the study period. ${ }^{1,3}$ It would be possible to redistribute patient volume to providers within institutions and jurisdictions. The overall number of providers caring for patients with PA would be reduced, but their proportion would be higher than the observed $3 \%$, and HV care could be compatible with provision of care close to home. An example would be disease specialization of oncologists within an institution, and in fact hematologic oncology studies have suggested that disease specialization within institutions is a common denominator of superior outcomes. ${ }^{14,44}$ Moreover, some patients may receive care from LV providers but still have a consultation with an HV provider, which occurred in $9 \%$ of patients in the LV group. Assessing the effect of such care delivery was beyond the scope of this study, but this could be further investigated to explore combined care models. Furthermore, other barriers to care access exist beyond provider expertise; in this analysis, only 7,062 of 10,881 diagnosed patients consulted a medical oncologist and were included in the provider-volume analysis. Our team has previously reported on disparities in assessment by medical oncologists and their detrimental effects on opportunity for therapy and on outcomes, which should be addressed to improve outcomes for patients with PA. ${ }^{45}$

Our study has some limitations. This was a retrospective cohort study using healthcare administrative datasets not collected specifically to address the research question, and therefore we did not have access to information regarding race, detailed disease characteristics, and specific chemotherapy regimen details, such as patterns of metastases or chemotherapy doses. There is a theoretical risk that patients treated by LV providers may have been incorrectly treated with systemic therapy rather than surgery. However, this would favor survival in the LV group. In addition, for reasons detailed previously, our analysis did not address facility-level case volume and focused on provider-level volume and variation. Finally, this analysis was conducted in the setting of publicly funded, universally accessible healthcare, which could impact generalizability to private or semiprivate practice settings. However, previous work has revealed that the attitudes of American and Canadian medical oncologists, respectively working in private and public healthcare systems, do not differ, and both share similar views regarding decision-making for chemotherapy. ${ }^{46}$ Moreover, surgical volume-outcome literature has confirmed similar results in European, American, and Canadian healthcare systems, showing the generalizability of such findings. ${ }^{1,4,47}$

\section{Conclusions}

Significant variation in receipt of chemotherapy and survival in the palliative management of PA was observed in association with provider volume. Care by HV providers was independently associated with higher odds of receiving chemotherapy and superior OS after adjusting for patient-level factors. This information is important to inform disease care pathways and care organization. If consistent volume-outcome relationships are confirmed in future studies, care delivery and system-level interventions may be considered to reduce variation and improve outcomes.

Submitted June 3, 2019; accepted for publication September 13, 2019.

Author contributions: Study concept and design: Hallet, Coburn. Data abstraction: Hallet, Davis, Beyfuss, Liu, Coburn. Data analysis and interpretation: All authors. Manuscript drafting, critical revision, and final approval: All authors.

Disclosures: Dr. Hallet has disclosed that she has received honoraria from Ipsen and Novartis Oncology. The remaining authors have disclosed that they have not received any financial consideration from any person or organization to support the preparation, analysis, results, or discussion of this article.

Funding: This study was supported by the Institute of Clinical Evaluative Sciences (ICES), which is funded by an annual grant from the Ontario Ministry of Health and Long-Term Care (MOHLTC). This study was supported by an operating grant from the Canadian Institutes of Health Research (ClHR; FRN \#154131).

Disclaimer: The opinions, results, and conclusions reported in this paper are those of the authors and are independent from the funding sources. No endorsement by ICES or the Ontario MOHLTC is intended or should be inferred. Parts of this material are based on data and information compiled and provided by the Canadian Institute for Health Information (CIHI). However the analyses, conclusions, opinions, and statements expressed herein are those of the authors and not necessarily those of $\mathrm{CIHI}$. Parts of this material are based on data and information provided by Cancer Care Ontario (CCO). The opinions, results, views, and conclusions reported in this paper are those of the authors and do not necessarily reflect those of $\mathrm{CCO}$. No endorsement by $\mathrm{CCO}$ is intended or should be inferred.

Correspondence: Julie Hallet, MD, MSc, Odette Cancer Centre, Sunnybrook Health Sciences Centre, 2075 Bayview Avenue, T2-063, Toronto, ON M4N 3M5, Canada. Email: julie.hallet@sunnybrook.ca 


\section{References}

1. Birkmeyer JD, Stukel TA, Siewers AE, et al. Surgeon volume and operative mortality in the United States. N Engl J Med 2003;349:2117-2127.

2. Gooiker GA, van Gijn W, Wouters MWJM, et al. Systematic review and meta-analysis of the volume-outcome relationship in pancreatic surgery. Br J Surg 2011;98:485-494

3. Bilimoria KY, Bentrem DJ, Feinglass JM, et al. Directing surgical quality improvement initiatives: comparison of perioperative mortality and longterm survival for cancer surgery. J Clin Oncol 2008;26:4626-4633.

4. Simunovic M, Urbach D, Major D, et al. Assessing the volume-outcome hypothesis and region-level quality improvement interventions: pancreas cancer surgery in two Canadian provinces. Ann Surg Oncol 2010;17: 2537-2544.

5. Gasper WJ, Glidden DV, Jin C, et al. Has recognition of the relationship between mortality rates and hospital volume for major cancer surgery in California made a difference? A follow-up analysis of another decade. Ann Surg 2009;250:472-483.

6. Allgood PC, Bachmann MO. Effects of specialisation on treatment and outcomes in screen-detected breast cancers in Wales: cohort study. Br J Cancer 2006;94:36-42.

7. Dikken JL, Dassen AE, Lemmens VEP, et al. Effect of hospital volume on postoperative mortality and survival after oesophageal and gastric cancer surgery in the Netherlands between 1989 and 2009. Eur J Cancer 2012; 48:1004-1013.

8. Fischer $\mathrm{C}$, Lingsma $\mathrm{H}$, Klazinga $\mathrm{N}$, et al. Volume-outcome revisited: the effect of hospital and surgeon volumes on multiple outcome measures in oesophago-gastric cancer surgery. PLoS One 2017;12:e0183955.

9. Swan RZ, Niemeyer DJ, Seshadri RM, et al. The impact of regionalization of pancreaticoduodenectomy for pancreatic cancer in North Carolina since 2004. Am Surg 2014;80:561-566.

10. Ireland $\mathrm{C}$, Wiedower $\mathrm{E}$, Mirza $\mathrm{M}$, et al. Impact of provider volume on outcomes of patients with Hodgkin lymphoma. World J Oncol 2018;9:46-49.

11. Huntington SF, Hoag JR, Zhu W, et al. Oncologist volume and outcomes in older adults diagnosed with diffuse large B cell lymphoma. Cancer 2018; 124:4211-4220.

12. Go RS, Bartley AC, Crowson CS, et al. Association between treatment facility volume and mortality of patients with multiple myeloma. J Clin Oncol 2017;35:598-604.

13. Go RS, Al-Hamadani M, Shah ND, et al. Influence of the treatment facility volume on the survival of patients with non-Hodgkin lymphoma. Cancer 2016;122:2552-2559.

14. Shanafelt TD, Kay NE, Rabe KG, et al. Hematologist/oncologist diseasespecific expertise and survival: lessons from chronic lymphocytic leukemia (CLL)/small lymphocytic lymphoma (SLL). Cancer 2012;118:1827-1837.

15. Institute of Medicine (US) and National Research Council (US) National Cancer Policy Board; Hewitt M, Petitti D, eds. Interpreting the Volume-Outcome Relationship in the Context of Cancer Care. Washington, DC: National Academies Press; 2001.

16. Siegel RL, Miller KD, Jemal A. Cancer statistics, 2017. CA Cancer J Clin 2017;67:7-30.

17. Sohal DPS, Kennedy EB, Khorana A, et al. Metastatic pancreatic cancer: ASCO clinical practice guideline update. J Clin Oncol 2018;36:2545-2556.

18. Conroy T, Desseigne F, Ychou M, et al. FOLFIRINOX versus gemcitabine for metastatic pancreatic cancer. N Engl J Med 2011;364:1817-1825.

19. Von Hoff DD, Envin $T$, Arena FP, et al. Increased survival in pancreatic cancer with nab-paclitaxel plus gemcitabine. N Engl J Med 2013;369:1691-1703.

20. Government of Canada, Health Canada. Canada Health Act - Health Care System - Health Canada. Available at: http://www.canada.ca/en/healthcanada/services/health-care-system/canada-health-care-system-medicare/ canada-health-act.html. Accessed January 2020

21. Robles SC, Marrett LD, Clarke EA, et al. An application of capturerecapture methods to the estimation of completeness of cancer registration. J Clin Epidemiol 1988;41:495-501.

22. Iron K, Zagorski BM, Sykora K, Manuel DG. Living and Dying in Ontario: An Opportunity for Improved Health Information. ICES Investigative Report. Toronto, Ontario: Institute for Clinical Evaluative Sciences; 2008.

23. Booth CM, Nanji S, Wei X, et al. Use and effectiveness of adjuvant chemotherapy for stage III colon cancer: a population-based study. J Natl Compr Canc Netw 2016;14:47-56.
24. Alter DA, Naylor CD, Austin P, et al. Effects of socioeconomic status on access to invasive cardiac procedures and on mortality after acute myocardial infarction. N Engl J Med 1999;341:1359-1367.

25. Kralj B. Measuring "rurality" for purposes of health-care planning: an empirical measure for Ontario. Ont Med Rev 2000;67:33-52.

26. Wilkins R. Use of postal codes and addresses in the analysis of health data. Health Rep 1993;5:157-177.

27. Weiner JP, Starfield BH, Steinwachs DM, et al. Development and application of a population-oriented measure of ambulatory care case-mix. Med Care 1991;29:452-472.

28. Reid RJ, MacWilliam L, Verhulst $L$, et al. Performance of the ACG case-mix system in two Canadian provinces. Med Care 2001;39:86-99.

29. Nam RK, Cheung P, Herschorn S, et al. Incidence of complications other than urinary incontinence or erectile dysfunction after radical prostatectomy or radiotherapy for prostate cancer: a population-based cohort study. Lancet Oncol 2014;15:223-231.

30. Rabeneck L, Paszat LF, Rothwell DM, et al. Temporal trends in new diagnoses of colorectal cancer with obstruction, perforation, or emergency admission in Ontario: 1993-2001. Am J Gastroenterol 2005;100:672-676.

31. Kagedan DJ, Abraham L, Goyert N, et al. Beyond the dollar: influence of sociodemographic marginalization on surgical resection, adjuvant therapy, and survival in patients with pancreatic cancer. Cancer 2016;122:3175-3182.

32. Kaplan EL, Meier P. Nonparametric estimation from incomplete observations. J Am Stat Assoc 2012;6:128-132.

33. Gastwirth JL, Gel YR, Miao W. The impact of Levene's test of equality of variances on statistical theory and practice. Stat Sci 2009;24:343-360.

34. Cunningham D, Allum WH, Stenning SP, et al. Perioperative chemotherapy versus surgery alone for resectable gastroesophageal cancer. N Engl J Med 2006;355:11-20.

35. André $T$, Boni $C$, Navarro $M$, et al. Improved overall survival with oxaliplatin, fluorouracil, and leucovorin as adjuvant treatment in stage II or III colon cancer in the MOSAIC trial. J Clin Oncol 2009;27:3109-3116.

36. Bang YJ, Van Cutsem E, Feyereislova A, et al. Trastuzumab in combination with chemotherapy versus chemotherapy alone for treatment of HER2positive advanced gastric or gastro-oesophageal junction cancer (ToGA): a phase 3, open-label, randomised controlled trial. Lancet 2010;376:687-697.

37. Hammad N, Cosby R, Biagi J, et al. The use of FOLFIRINOX as first-line treatment for metastatic pancreatic adenocarcinoma. Toronto, Ontario: Cancer Care Ontario; June 23, 2011. Available at: https://pdfs.semanticscholar.org/0e0f/98022db4be06e3b3793fbc489fda45cad836.pdf. Accessed December 20, 2019.

38. Wennberg JE. Unwarranted variations in healthcare delivery: implications for academic medical centres. BMJ 2002;325:961-964.

39. Goodman DC. Unwarranted variation in pediatric medical care. Pediatr Clin North Am 2009;56:745-755.

40. Mercuri M, Gafni A. Medical practice variations: what the literature tells us (or does not) about what are warranted and unwarranted variations. J Eval Clin Pract 2011;17:671-677.

41. Sepucha K, Ozanne E, Mulley AG Jr. Doing the right thing: systems support for decision quality in cancer care. Ann Behav Med 2006;32:172-178.

42. Halm EA, Lee C, Chassin MR. Is volume related to outcome in health care? A systematic review and methodologic critique of the literature. Ann Intern Med 2002;137:511-520.

43. Thiemann DR, Coresh J, Oetgen WJ, et al. The association between hospital volume and survival after acute myocardial infarction in elderly patients. N Engl J Med 1999;340:1640-1648.

44. Loberiza FR Jr, Cannon AJ, Weisenburger DD, et al. Survival disparities in patients with lymphoma according to place of residence and treatment provider: a population-based study. J Clin Oncol 2009;27:5376-5382.

45. Mavros MN, Xu L, Maqsood H, et al. Perioperative blood transfusion and the prognosis of pancreatic cancer surgery: systematic review and metaanalysis. Ann Surg Oncol 2015;22:4382-4391.

46. Berry SR, Bell CM, Ubel PA, et al. Continental divide? The attitudes of US and Canadian oncologists on the costs, cost-effectiveness, and health policies associated with new cancer drugs. J Clin Oncol 2010;28:4149-4153.

47. Kagedan DJ, Goyert N, Li Q, et al. The impact of increasing hospital volume on 90-day postoperative outcomes following pancreaticoduodenectomy. J Gastrointest Surg 2017;21:506-515 
Supplemental online content for:

\section{Benefits of High-Volume Medical Oncology Care for Noncurable Pancreatic Adenocarcinoma: A Population-Based Analysis}

Julie Hallet, MD, MSc; Laura Davis, MSc; Alyson Mahar, PhD; Michail Mavros, MD; Kaitlyn Beyfuss, MSc; Ying Liu, MSc; Calvin H.L. Law, MD, MPH; Craig Earle, MD, MSc; and Natalie Coburn, MD, MPH

J Natl Compr Canc Netw 2020;18(3):297-303

eFigure 1: Flow Diagram of Cohort Creation eTable 1: Main Variable Definitions Using Ontario Healthcare Databases eTable 2: Number of Patients, Stratified by Provider Volume eTable 3: Number of Patients per Provider Volume Quintile 


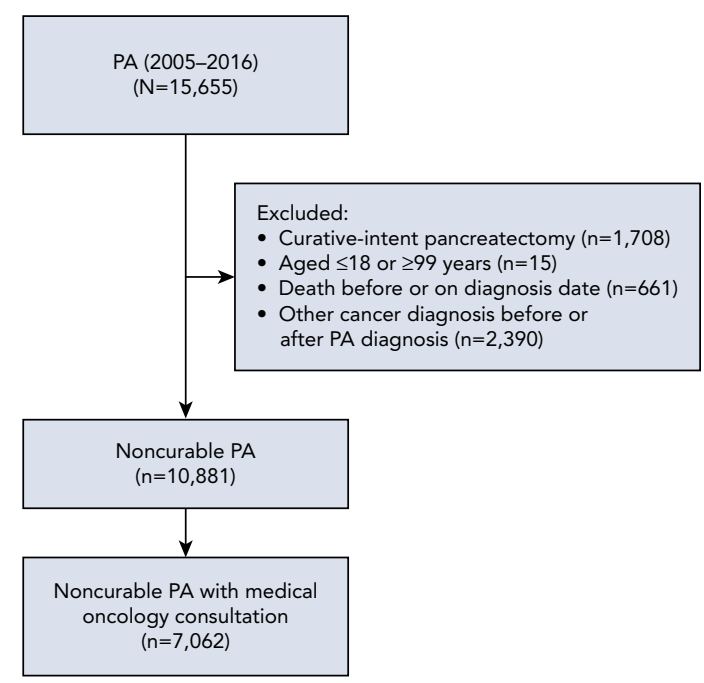

eFigure 1. Flow diagram of cohort creation.

Abbreviation: PA, pancreatic adenocarcinoma.

\section{eTable 1. Main Variable Definitions Using Ontario Healthcare Databases}

\begin{tabular}{|c|c|c|}
\hline Variable & Data Source & Code Strategy \\
\hline Pancreatic adenocarcinoma & OCR & $\begin{array}{l}\text { ICD-O-3 topography: C25.0-25.9, and morphology: 8000, 8001, 8010, 8020, } \\
8021,8031,8035,8140,8144,8145,8255,8340,8341,8344,8440,8442, \\
8470,8481,8490,8500,8560,8570,8574,8575,9990\end{array}$ \\
\hline Pancreatectomy (exclusion) & $\begin{array}{l}\mathrm{ClHI} \\
\mathrm{OHIP}\end{array}$ & $\begin{array}{l}\text { Pancreaticoduodenectomy: } 10 \text { K87 } \\
\text { Total pancreatectomy: 1OK91, 1OJ89, 10K89 } \\
\text { Distal pancreatectomy: 1OJ87 (except for 1OJ87VC) or OHIP codes S300, } \\
\text { S299, S309, S301 }\end{array}$ \\
\hline Age at diagnosis & OCR & - \\
\hline Sex & RPDB & - \\
\hline Income quintile & RPDB & Ecologic measure of income ${ }^{a}$ \\
\hline Rural residence & RPDB & Rural index of Ontario ${ }^{b}$ \\
\hline Year of diagnosis & OCR & - \\
\hline Comorbidity burden & $\begin{array}{l}\mathrm{ClHI} \text { Discharge Abstract Database } \\
\mathrm{CIHI} \text { same-day surgery } \\
\text { OHIP }\end{array}$ & ICD codes for Johns Hopkins Adjusted Clinical Groups ${ }^{c, d}$ \\
\hline Medical oncology consultation & OHIP & $\begin{array}{l}\text { OHIP codes: A445, A130, A131, A135, A615, A446, A435, A655, A845, A136, } \\
\text { A616, A443, A133, A613, A441, A611, A444, A134, A614, A448, A138, A618, } \\
\text { C445, C845, C446, C443, C444 }\end{array}$ \\
\hline Medical oncology provider & OHIP & $\begin{array}{l}\text { Provider with >1 billing of chemotherapy: OHIP codes G381, G281, G339, } \\
\text { G345, G359 }\end{array}$ \\
\hline Receipt of chemotherapy & $\begin{array}{l}\text { OHIP } \\
\text { ALR }\end{array}$ & $\begin{array}{l}\geq 1 \text { cycle of chemotherapy defined as OHIP codes: G381, G281, G339, G345, } \\
\text { G359 or ALR drug codes: S1, S17, S24 (counted only once if both ALR and } \\
\text { OHIP codes are present) }\end{array}$ \\
\hline Death & RPDB & Date of death \\
\hline
\end{tabular}

Abbreviations: ALR, Cancer Activity Level Reporting; CIHI, Canadian Institute for Health Information; OCR, Ontario Cancer Registry; OHIP, Ontario Health Insurance Plan; RPDB, Registered Persons Database.

${ }^{a}$ Alter DA, Naylor CD, Austin P, Tu JV. Effects of socioeconomic status on access to invasive cardiac procedures and on mortality after acute myocardial infarction. N Engl J Med 1999;341:1359-1367.

'Du Plessis V, Beshiri R, Bollman RD, Clemenson H. Definitions of "rural." Rural and Small Town Canada Analysis Bulletin, 3. Ottawa, Ontario, Canada: Statistics Canada; 2001.

cReid RJ, Roos NP, MacWilliam L, et al. Assessing population health care need using a claims-based ACG morbidity measure: a validation analysis in the Province of Manitoba. Health Serv Res 2002;37:1345-1364.

dReid RJ, MacWilliam L, Verhulst L, et al. Performance of the ACG case-mix system in two Canadian provinces. Med Care 2001;39:86-99. 


\section{eTable 2. Number of Patients, Stratified by} Provider Volume $(\mathrm{N}=7,062)$

\begin{tabular}{|c|c|c|}
\hline Provider Volume & Patients, $\mathbf{n}$ & Percentile \\
\hline 1 & 51 & 0.7 \\
\hline 2 & 214 & 3.7 \\
\hline 3 & 278 & 7.7 \\
\hline 4 & 402 & 13.4 \\
\hline 5 & 488 & 20.3 \\
\hline 6 & 698 & 30.2 \\
\hline 7 & 707 & 40.2 \\
\hline 8 & 515 & 47.5 \\
\hline 9 & 708 & 57.5 \\
\hline 10 & 224 & 60.7 \\
\hline 11 & 500 & 67.8 \\
\hline 12 & 339 & 72.6 \\
\hline 13 & 271 & 76.4 \\
\hline 14 & 159 & 78.6 \\
\hline 15 & 88 & 79.9 \\
\hline 16 & 94 & 81.2 \\
\hline 17 & 38 & 81.8 \\
\hline 19 & 189 & 84.4 \\
\hline 22 & 226 & 87.6 \\
\hline 23 & 113 & 89.2 \\
\hline 25 & 147 & 91.3 \\
\hline 38 & 269 & 95.1 \\
\hline 49 & 245 & 98.6 \\
\hline 55 & 99 & 100.0 \\
\hline
\end{tabular}

\section{eTable 3. Number of Patients per Provider Volume} Quintile ( $N=7,062)$

\begin{tabular}{|lccc|}
\hline $\begin{array}{l}\text { Provider Volume } \\
\text { Quintile }\end{array}$ & Patients, n & $\begin{array}{c}\text { Proportion of } \\
\text { Patients } \\
\text { (\%) }\end{array}$ & Percentile \\
\hline 1 & 1,433 & 20.2 & 20 \\
\hline 2 & 1,405 & 19.9 & 40 \\
\hline 3 & 1,447 & 20.5 & 60 \\
\hline 4 & 1,451 & 20.5 & 80 \\
\hline 5 & 1,326 & 18.8 & 100 \\
\hline
\end{tabular}

